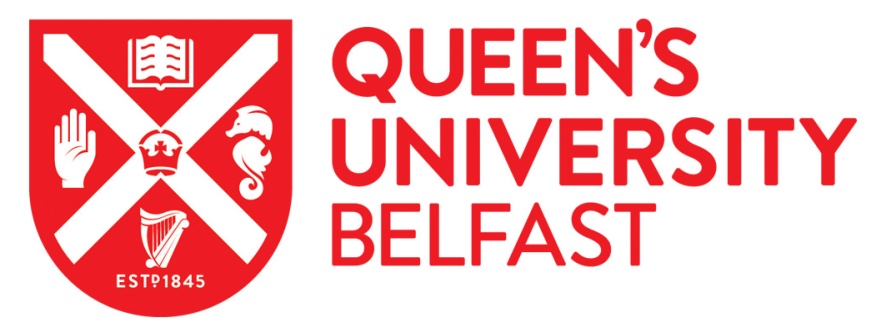

\title{
Cardiac sub-volume targeting demonstrates regional radiosensitivity in the mouse heart
}

Ghita, M., Gill, E., Walls, G., Edgar, K., McMahon, S., Vasquez Osorio, E., Bergom, C., Grieve, D., Watson, C., McWilliam, A., Aznar, M., van herk, M., Williams, K. J., \& Butterworth, K. (2020). Cardiac sub-volume targeting demonstrates regional radiosensitivity in the mouse heart. Radiotherapy and Oncology: Journal of the European Society for Therapeutic Radiology and Oncology, [DOI: 10.1016/j.radonc.2020.07.016 ]. https://doi.org/10.1016/j.radonc.2020.07.016, https://doi.org/10.1016/j.radonc.2020.07.016

Published in:

Radiotherapy and Oncology: Journal of the European Society for Therapeutic Radiology and Oncology

\section{Document Version:}

Peer reviewed version

\section{Queen's University Belfast - Research Portal:}

Link to publication record in Queen's University Belfast Research Portal

\section{Publisher rights}

Copyright 2020 Elsevier

This manuscript is distributed under a Creative Commons Attribution-NonCommercial-NoDerivs License

(https://creativecommons.org/licenses/by-nc-nd/4.0/), which permits distribution and reproduction for non-commercial purposes, provided the author and source are cited.

\section{General rights}

Copyright for the publications made accessible via the Queen's University Belfast Research Portal is retained by the author(s) and / or other copyright owners and it is a condition of accessing these publications that users recognise and abide by the legal requirements associated with these rights.

\section{Take down policy}

The Research Portal is Queen's institutional repository that provides access to Queen's research output. Every effort has been made to ensure that content in the Research Portal does not infringe any person's rights, or applicable UK laws. If you discover content in the Research Portal that you believe breaches copyright or violates any law, please contact openaccess@qub.ac.uk. 


\section{Abstract}

Background and purpose: Radiation-induced cardiac toxicity (RICT) remains one of the most critical dose limiting constraints in radiotherapy. Recent studies have shown higher doses to the base of the heart are associated with worse overall survival in lung cancer patients receiving radiotherapy. This work aimed to investigate the impact of sub-volume heart irradiation in a mouse model using small animal image-guided radiotherapy.

Materials and Methods: C57BL/6 mice were irradiated with a single fraction of 16 Gy to the base, middle or apex of the heart using a small animal radiotherapy research platform. Cone beam CT and echocardiography were performed at baseline and at 10 week intervals until 50 weeks post-treatment. Structural and functional parameters were correlated with mean heart dose (MHD) and volume of heart receiving 5 Gy (V5).

Results: All irradiated mice showed a time dependent increase in left ventricle wall thickness in diastole of $\sim 0.2 \mathrm{~mm}$ detected at 10 weeks post-treatment, with the most significant and persistent changes occurring in the heart base-irradiated animals. Similarly, statistically different functional effects $(\mathrm{p}<0.01)$ were observed in base-irradiated animals which showed the most significant decreases compared to controls. The observed functional changes did not correlate with MHD and V5 $\left(\mathrm{R}^{2}<0.1\right)$, indicating that whole heart dosimetry parameters do not predict physiological changes resulting from cardiac sub-volume irradiation.

Conclusions: This is the first report demonstrating the structural and functional consequences of sub-volume targeting in the mouse heart and reverse translates clinical observations indicating the heart base as a critical radiosensitive region. 


\section{Introduction}

Radiation therapy (RT) is part of definitive treatment for patients with unresectable non-small cell lung cancer (NSCLC). Despite major technological advances in imaging and conformal delivery techniques, the tolerances of adjacent normal tissues continue to limit target volume doses $[1,2]$. In patients receiving RT for thoracic malignancies, the most frequent toxicities occur in the lungs and/or heart. Radiation-induced cardiac toxicity (RICT) may present as multiple pathologies including myocardial fibrosis, ischemic heart disease, valvular abnormalities and pericarditis [3]. RICT often manifests many years following radiation exposure [4,5]. However, recent data suggests that severe radiation-induced cardiac dysfunction in NSCLC patients may manifest within 2 years of treatment with definitive RT [6]. In the absence of a clear dose/volume consensus for RICT in the treatment of NSCLC [7], there has been an increased awareness of the potential role of cardiac substructures in the development of RICT [8]. Furthermore, dose to undefined anatomical heart regions has recently been shown to correlate with survival, and the base of the heart was identified as a radiosensitive sub-region with a threshold of around 8.5 Gy $[9,10]$.

Preclinical studies interrogating the underlying pathophysiological mechanism of RICT have previously used whole body, whole thorax or whole heart irradiation techniques, which do not accurately recapitulate clinical exposure scenarios [3]. Currently, no preclinical study has reported on the functional significance of sub-volume heart irradiation as a translationally relevant approach to mechanistically explore the underlying molecular basis of RICT. In the current study, we report the first observations of the structural and functional consequences of irradiated cardiac sub-volumes using small-animal image guided RT. 


\section{Materials and Methods}

\section{Animals and Maintenance}

RICT was investigated in female 12-15 week old C57BL/6J mice obtained from Charles River Laboratories (Oxford, UK). All mice were housed under controlled conditions (12 hour lightdark cycle, $21^{\circ} \mathrm{C}$ ) in standard caging with three to five littermates and received a standard laboratory diet (Teklad, Envigo, UK) with water ad libitum. Environmental enrichment was provided using nesting material, cardboard tubes and softwood blocks. Mice were also handled gently and frequently from a young age to reduce stress. Prior to irradiation, animals were anaesthetised with ketamine and xylazine $(100 \mathrm{mg} / \mathrm{kg}$ and $10 \mathrm{mg} / \mathrm{kg})$ by intraperitoneal injection. Based on previous studies, the variation in Myocardial Performance Index (MPI) within each group was expected to be approximately $15 \%$. In this study, animal numbers were chosen to give power to detect differences in MPI of $25 \%$ with a power of $80 \%$ for a 2 -sided equality test with a significance threshold of 0.05 which required at least six mice per group. Mice weights were monitored throughout the experiment showing minor fluctuations but remained within tolerated weight loss of $<15 \%$. All experimental procedures were carried out in accordance with the Home Office Guidance on the Operation of the Animals (Scientific Procedures) Act 1986, published by Her Majesty's Stationary Office, London, and approved by the institutional Animal Welfare and Ethical Review Body (PPL2813).

\section{Imaging, treatment planning and irradiation}

Mice were irradiated with $220 \mathrm{kVp}$ X-rays under CBCT image guidance using a Small Animal Radiation Research Platform (SARRP, Xstrahl Life Sciences) calibrated using the Institute of Physics and Engineering in Medicine and Biology (IPEMB) code of practice [11]. Mice were randomly assigned to experimental groups prior to irradiation with a single fraction dose of 16 Gy delivered using a parallel opposed, anterior-posterior beam geometry, with a 3 x $9 \mathrm{~mm}$ 
collimator (dose rate $2.67 \pm 0.11 \mathrm{~Gy} / \mathrm{min}$ ). A single isocentre was selected targeting the base, middle or apex of the heart with 6 animals used in each treatment group.

CBCT scans were performed before irradiation and the heart was outlined on the pre-treatment CBCT scan. Dose-volume histograms (DVHs) were calculated for each mouse using Muriplan (Xstrahl Inc, Suwannee, GA) for whole heart and the mean dose was calculated for the targeted subvolume as well as the adjacent non-targeted sub-volumes (Supplementary Figure 1). Representative treatment plans from Muriplan for each of the cardiac sub-volumes are shown in Supplementary Figure 2. Dosimetric parameters including MHD and V5 were extracted from the individual DVHs using Matlab R2017a.

\section{Echocardiography}

Longitudinal transthoracic echocardiography (TTE) was performed at baseline and at 10, 20 40 and 50 weeks after irradiation to detect structural and functional cardiac abnormalities using a Vevo770® ultrasound system with a high-frequency $45 \mathrm{MHz}$ RMV707B scan head (VisualSonics Inc.). During TTE acquisition, animals were anaesthetised using $2 \%$ isoflurane. M-mode parasternal short-axis scans at the level of the papillary muscles were used to quantify left ventricle (LV) posterior wall thickness in diastole (LVPW), and derive the left ventricle fractional shortening (FS) and ejection fraction (EF). Pulse-wave Doppler was used to quantify diastolic function expressed as E/A ratio at the mitral valve and global cardiac function, expressed as Myocardial Performance Index (MPI). Observers were blinded to the experimental groups of the mice during data acquisition.

\section{Data and statistical analysis}

Statistical differences between populations were calculated using unpaired two-tailed Student t-tests, or one way ANOVA tests where appropriate, with a significance threshold of $p<0.05$. Data is presented either as the average for the entire experimental arm \pm standard error, or per 
individual mouse in correlation plots. Correlation between functional and dosimetric parameters was tested by fitting linear regression lines using Prism GraphPad Prism 5 (Version 8.0, GraphPad Software, Inc.) with the $\mathrm{R}^{2}$ values for MHD and V5 reported if significant. Statistical significance of slope parameters was calculated using an F-test comparing the linear regression model to a model with a slope of 0 .

\section{Results}

TTE measurements were analysed after irradiation of the base, middle and apex of the heart. Differential effects on LV systolic function were observed at 40 and 50 weeks post irradiation depending on the targeted sub-volume. As shown in Figures 1a and 1b, only mice in which the base of the heart was irradiated showed significant changes $(p<0.001)$ in FS which were significantly different to the middle and apex irradiated groups $(\mathrm{p}<0.01)$. Pulsed wave Doppler derived MPI is presented for each of the experimental groups in Figures 1c and 1d as an assessment of global cardiac function in mice at 40 and 50 weeks post-treatment. Significant changes were observed in all irradiated mice, with a highly significant increase for both base and middle irradiated animals $(\mathrm{p}<0.004)$. Changes in the EF were also observed and are shown in Supplementary Figure 3. Changes in MPI were less significant for apex irradiated mice $(\mathrm{p}=0.018)$ at 50 weeks post irradiation.

LV wall thickening after targeted irradiation was also evaluated and changes shown in Figures $2 \mathrm{a}$ and $2 \mathrm{~b}$. Significant alterations in the thickness of the LVPW were observed in all groups as early as 10 weeks post irradiation (Supplementary Figure 4) which persisted for the base and middle heart region irradiated mice at $20-50$ weeks $(\mathrm{p}<0.03)$. However, the increase in LVPW thickness in apex irradiated mice was smaller and not statistically significant $(p>0.1)$ at later time-points. 
Serial TTE performed at baseline and from 10 - 50 weeks showed significant differences in the base irradiated group throughout the study for all systolic functions $(\mathrm{p}<0.01)$. Animals in which the middle of the heart was irradiated showed statistically significant changes in the LVPW throughout the course of the study for the LV measurement only $(\mathrm{p}<0.001)$. No significant persistent changes were observed for the apex irradiated group $(\mathrm{p}>0.13)$ (Supplementary Figure 4). Furthermore, a significant decrease in the E/A ratio of early and late filling of the left ventricle, as presented in Figure $2 \mathrm{c}$ and $2 \mathrm{~d}$, indicates diastolic dysfunction at 50 weeks post treatment for the base-irradiated mice only $(\mathrm{p}=0.002)$.

MHD and V5 were derived from the DVHs for individual mice (Figures 3a-c) and correlated with functional and structural parameters. As shown in Figure 3a, the heart anatomy leads to variation in the irradiated volume and mean dose delivered for all experimental arms. An average mean dose of $8.6 \pm 1.8$ Gy was delivered to the middle region cohort which had the highest volume of the heart irradiated. Base-irradiated animals received an average of 7.0 \pm 2.1 Gy followed by the apex irradiated mice with an MHD average of $5.9 \pm 0.3$ Gy.In addition, mean lung dose (MLD) in the left lung did not correlate with functional changes. Baseirradiated animals had the lowest MLD (2.3 Gy), followed by the middle (3.4 Gy) and apex (7.0 Gy) irradiated animals.

V5 showed similar trends to the MHD (Figure 4 a) where middle irradiated mice had $55 \pm 14 \%$ heart volume irradiated with 5 Gy or more, whilst base-irradiated animals had $46 \pm 11 \%$ heart volume irradiated with $\geq 5$ Gy. Apex irradiated animals had only $37 \pm 7 \%$ heart volume irradiated with $\geq 5$ Gy. Similar to the observed correlations with MHD, no correlations were detected for FS or MPI $\left(\mathrm{R}^{2}<0.05\right)$.

\section{Discussion}


RICT can manifest as multiple pathologies following thoracic radiation exposure [12]. However, the process from acute injury to progressive cardiac disease, and the relationship between short-term effects and long-term risks in individual patients remain unclear. With improved cancer survival [13], longer term side effects from radiation therapy are increasingly important [14]. In patients receiving radiotherapy, the risk of future structural and functional abnormalities in the coronary vessels, valves, pericardium or myocardium is thought to correlate with radiation dose to the heart [15]. However, a recent systematic review was unable to conclude which dosimetric parameters are clinically relevant in the development of RICT based on the present literature [7]. Whilst post-hoc analyses of clinical trials and retrospective dosimetry studies identify the association of heart dose with survival after treatment for NSCLC, a major limitation of these studies is the lack of cause of death data and the absence of dosimetry reporting for smaller pre-defined sub-volumes $[9,16]$.

Whilst acknowledging the potential challenges of modelling radiation therapy response in mice [17] we have, for the first time, directly recapitulated clinical observations highlighting the base of the heart as a radiosensitive substructure. In our model, radiation dose to the base of the heart leads to systolic dysfunction manifested as decreased FS and EF compared to nonirradiated age-matched controls. Changes in cardiac function after irradiation of the middle or apex of the heart were modest and non-significant $(\mathrm{p}>0.06)$. These observations are similar to those reported previously by Kitahara and colleagues, who showed irradiation of the atria leads to a different and faster type of radiation damage compared to irradiation to the ventricles alone following local heart irradiation or intravenous adriamycin on the cardiovascular system of Wistar rats [18].

RICT is manifested as multiple late occurring pathologies following radiation exposure, yet the critical target cell types and mechanisms of response remain to be fully determined. In keeping with clinical investigators $[9,10]$ we hypothesise that the observed effects may be 
due to the presence of critical vascular structures including the aorta, superior vena cava and coronary arteries, or pacemaker tissues central to the cardiac conduction system including the sinoatrial and atrioventricular nodes. Cardiac structures located in sub-volumes of that heart shown to be radiosensitive in clinical studies are summarized in table $1[10,19-26]$. In addition, the atria located in the base, also have important endocrine functions mediated by hormones including cardiac natriuretic peptides, and adrenomedullin, which work to coordinate the function of other cardiovascular organs [27], and may be impacted by radiation exposure.

Our model has significant potential for further investigation of the underlying molecular basis and functional consequences of RICT which may include exploring cardio-pulmonary interactions where radiation damage to the heart has previously shown to enhance early functional loss in the irradiated lung [28]. These interactions could be important in the presented study, considering that differences in the geometry of the irradiated heart subvolumes led to variation in the irradiated lung volumes (Supplementary Figure 5). However, it is important to acknowledge that whilst mouse models have utility in cardiovascular research studies, they only recapitulate some of the characteristics of the human disease phenotype and typically do not accurately capture all aspects of human cardiovascular disease which may limit interpretation of our experimental data [29]. In addition, our study was also limited to data acquired using only female mice and at a single dose and single fraction.

The differential effects observed in base-irradiated mice and lack of a clear correlation with global parameters such as MHD and V5 are in good agreement with the reported clinical findings in RICT following treatment for NSCLC [7,9]. Further investigations into the specific biological mechanisms driving the differential regional responses in the heart are therefore justified. Finally, the development of RICT is known to be accelerated by the contributing comorbidity factors such as obesity or diabetes $[4,16]$. The preclinical RICT model developed 
in this study, aided by the novel preclinical image guided radiotherapy and functional analysis techniques may prove invaluable to explore clinically relevant RICT risk factors.

We have, for the first time, applied small animal image-guided RT to demonstrate the structural and functional impacts of dose to different sub-volumes of the heart. No consistent correlations were observed between mean dose or V5 and TTE parameters indicating unique physiological mechanisms not solely driven by averages measures of physical dose deposition across the whole heart.

\section{Conflict of interest}

None

\section{Acknowledgements}

This work was funded by the Tom Simms Memorial Fund and the Queen's University Foundation. GW is supported is supported by the Irish Clinical Academic Training (ICAT) Programme, funded by the Wellcome Trust and the Health Research Board (Grant Number 203930/B/16/Z), the Health Service Executive, National Doctors Training and Planning and the Health and Social Care, Research and Development Division, Northern Ireland. KSE and DJG are supported by the British Heart Foundation (PG/15/18/31333). MVH is supported by the NIHR Manchester Biomedical Research Centre. KJW and MVH are supported by Cancer Research UK via the Cancer Research Manchester Centre (C147/A25254) and RadNet Manchester (C19941/A28701).

\section{References}

[1] Brown S, Banfill K, Aznaar M, Whitehurst P, Faivre Finn C. The evolving role of radiotherapy in non-small cell lung cancer. Br J Radiol 2019;92. 
[2] Gagliardi G, Constine LS, Moiseenko V, Correa C, Pierce LJ, Allen AM, et al. Radiation dose-volume effects in the heart. Int J Radiat Oncol Biol Phys 2010;76:S7785. https://doi.org/10.1016/j.ijrobp.2009.04.093.

[3] Schlaak RA, SenthilKumar G, Boerma M, Carmen Bergom. Advances in Preclinical Research Models of Radiation-Induced Cardiac Toxicity. Cancers (Basel) 2020;12:415.

[4] Darby SC, Cutter DJ, Boerma M, Constine LS, Fajardo LF, Kodama K, et al. Radiation-related heart disease: current knowledge and future prospects. Int J Radiat Oncol Biol Phys 2010;76:656-665. https://doi.org/10.1161/CIRCULATIONAHA.110.956839.

[5] Taylor C, Duane FK, Dodwell D, Gray R, Wang Z, Wang Y, et al. Estimating the Risks of Breast cancer radiotherapy: Evidence from modern radiation doses to the lungs and Heart and From previous randomized trials. J Clin Oncol 2017;35:1641-9. https://doi.org/10.1200/JCO.2016.72.0722.

[6] Chun SG, Hu C, Choy H, Komaki RU, Timmerman RD, Schild SE, et al. Impact of intensity-modulated radiation therapy technique for locally advanced non-small-cell lung cancer: A secondary analysis of the NRG oncology RTOG 0617 randomized clinical trial. J Clin Oncol 2017;35:56-62. https://doi.org/10.1200/JCO.2016.69.1378.

[7] Zhang TW, Snir J, Boldt RG, Rodrigues GB, Louie A V, Gaede S, et al. Is the Importance of Heart Dose Overstated in the Treatment of Non-Small Cell Lung Cancer? A Systematic Review of the Literature. Int J Radiat Oncol Biol 2019;104:582-9. https://doi.org/10.1016/j.ijrobp.2018.12.044.

[8] Wang K, Pearlstein KA, Patchett ND, Deal AM, Mavroidis P, Jensen BC, et al. Heart dosimetric analysis of three types of cardiac toxicity in patients treated on dose- 
escalation trials for Stage III non-small-cell lung cancer. Radiother Oncol 2017;125:293-300. https://doi.org/10.1016/j.radonc.2017.10.001.

[9] McWilliam A, Kennedy J, Hodgson C, Vasquez Osorio E, Faivre-Finn C, van Herk M. Radiation dose to heart base linked with poorer survival in lung cancer patients. Eur J Cancer 2017;85:106-13. https://doi.org/10.1016/j.ejca.2017.07.053.

[10] Stam B, Peulen H, Guckenberger M, Mantel F, Hope A, Werner-Wasik M, et al. Dose to heart substructures is associated with non-cancer death after SBRT in stage I-II NSCLC patients. Radiother Oncol 2017;123:370-5. https://doi.org/10.1016/j.radonc.2017.04.017.

[11] Rosser KE. The IPEMB code of practice for the determination of absorbed dose for $\mathrm{x}-$ rays below $300 \mathrm{kV}$ generating potential (0.035 mm Al-4 mm Cu HVL; 10-300 kV generating potential). Institution of Physics and Engineering in Medicine and Biology. Phys Med Biol 1996;41:2605-25. https://doi.org/10.1088/0031-9155/50/12/001.

[12] Wang K, Eblan MJ, Deal AM, Lipner M, Zagar TM, Wang Y, et al. Cardiac toxicity after radiotherapy for stage III non-small-cell lung cancer: Pooled analysis of doseescalation trials delivering 70 to 90 Gy. J Clin Oncol 2017;35:1387-94. https://doi.org/10.1200/JCO.2016.70.0229.

[13] Siegel RL, Miller KD, Jemal A. Cancer statistics, 2020. CA Cancer J Clin 2020;70:730. https://doi.org/10.3322/caac.21590.

[14] Shahrokni A, Wu A, Carter J, Stuart M. Lichtman. Long Term Toxicity of Cancer Treatment in Older Patients Armin. Clin Geriatr Med 2016;32:63-80. https://doi.org/10.1016/j.physbeh.2017.03.040.

[15] Atkins KM, Rawal B, Chaunzwa TL, Lamba N, Bitterman DS, Williams CL, et al. 
Cardiac Radiation Dose, Cardiac Disease, and Mortality in Patients With Lung Cancer. J Am Coll Cardiol 2019;73:2976-87. https://doi.org/10.1016/j.jacc.2019.03.500.

[16] Van Den Bogaard VAB, Ta BDP, Van Der Schaaf A, Bouma AB, Middag AMH, Bantema-Joppe EJ, et al. Validation and modification of a prediction model for acute cardiac events in patients with breast cancer treated with radiotherapy based on threedimensional dose distributions to cardiac substructures. J Clin Oncol 2017;35:1171-8. https://doi.org/10.1200/JCO.2016.69.8480.

[17] Butterworth KT. Evolution of the Supermodel: Progress in Modelling Radiotherapy Response in Mice. Clin Oncol 2019;31:272-82. https://doi.org/10.1016/j.clon.2019.02.008.

[18] Kitahara T, Liu K, Solanki K, Trott KR. Functional and morphological damage after local heart irradiation and/or adriamycin in Wistar rats. Radiat Oncol Investig 1993;1:198-205. https://doi.org/10.1002/roi.2970010403.

[19] Ma J-T, Sun L, Sun X, Xiong Z-C, Liu Y, Zhang S-L, et al. Is pulmonary artery a dose-limiting organ at risk in non-small cell lung cancer patients treated with definitive radiotherapy? Radiat Oncol 2017;12.

[20] van den Bogaard VAB, van Luijk P, Hummel YM, van der Meer P, Schuit E, Boerman LM, et al. Cardiac Function After Radiation Therapy for Breast Cancer. Int J Radiat Oncol Biol Phys 2019;104:392-400. https://doi.org/10.1016/j.ijrobp.2019.02.003.

[21] Vivekanandan S, Landau DB, Counsell N, Warren DR, Khwanda A, Rosen SD, et al. The Impact of Cardiac Radiation Dosimetry on Survival After Radiation Therapy for Non-Small Cell Lung Cancer. Int J Radiat Oncol Biol Phys 2017;99:51-60. https://doi.org/10.1016/j.ijrobp.2017.04.026. 
[22] Cozzarín A, Cianciulli TF, Saccheri MC, Lax JA, Simonetti ME, Zappi A, et al. Severe Mitral Regurgitation after Radiotherapy. Echocardiography 2013;31:E37-40.

[23] Gujral DM, Y BNS, Chahal NS, Senior R, Harrington KJ, Nutting CM. Clinical Features of Radiation-induced Carotid Atherosclerosis. Clin Oncol 2013;10:1-9.

[24] Wong OY, Yau V, Kang J, Glick D, Lindsay P, Le LW, et al. Survival Impact of Cardiac Dose Following Lung Stereotactic Body Radiotherapy. Clin Lung Cancer 2018;19:e241-6. https://doi.org/10.1016/j.cllc.2017.08.002.

[25] Piroth MD, Baumann R, Budach W, Dunst J, Feyer P, Fietkau R, et al. Heart toxicity from breast cancer radiotherapy : Current findings, assessment, and prevention. Strahlentherapie Und Onkol 2019;195:1-12.

[26] Yegya-Raman N, Wang K, Kim S, Reyhan M, Deek MP, Sayan M, et al. Dosimetric Predictors of Symptomatic Cardiac Events After Conventional-Dose Chemoradiation Therapy for Inoperable NSCLC. J Thorac Oncol 2018;10:1058-518.

[27] Ogawa T, de Bold AJ. The heart as an endocrine organ. Endocr Connect 2014;3:R3144. https://doi.org/10.1530/EC-14-0012.

[28] Van Luijk P, Novakova-Jiresova A, Faber H, Schippers JM, Kampinga HH, Meertens $\mathrm{H}$, et al. Radiation damage to the heart enhances early radiation-induced lung function loss. Cancer Res 2005;65:6509-11. https://doi.org/10.1158/0008-5472.CAN-05-0786.

[29] Milani-Nejad N, Janssen P. Small and large animal models in cardiac contraction research: advantages and disadvantages. Pharmacol Ther 2014:235-249. 


\section{Figure Legends}

Figure 1. Cardiac systolic and performance changes after irradiation measured as: FS at a) 40 weeks and b) 50 weeks post treatment. MPI was assessed at c) 40 and d) 50 weeks post treatment. Data are presented as an average of 6 mice per treatment group \pm standard error of the mean. Significance values were classified as $* \mathrm{P}<.05, * * \mathrm{P}<.01$ and $* * * \mathrm{P}<.001$.

Figure 2. Cardiac structural and diastolic changes after irradiation measured as: LVPW thickness at a) 40 weeks and b) 50 weeks post treatment and E/A ratio at c) 40 and d) 50 weeks post treatment. Data are presented as an average of 6 mice per treatment group \pm standard error of the mean. Significance values were classified as $* \mathrm{P}<.05, * * \mathrm{P}<.01$ and $* * * \mathrm{P}<.001$.

Figure 3. a) Average MHD for all the experimental groups. Physiological effects correlated against the mean dose for the specific irradiated sub-volume for individual mice: b) FS, c) MPI and d) LVPW thickening. Black triangles: base-irradiated mice; dark grey squares: middle irradiated mice; light grey circles: apex irradiated mice. $* \mathrm{P}<.05, * * \mathrm{P}<.01$ and $* * * \mathrm{P}<.001$.

Figure 4. a) Average heart volume receiving 5 Gy or more for all the experimental groups. Physiological effects correlated against V5 calculated for individual mice: b) FS, c) MPI and d) LVPW thickening. Black triangles: base irradiated mice; dark grey squares: middle irradiated mice; light grey circles: apex irradiated mice. ${ }^{*} \mathrm{P}<.05, * * \mathrm{P}<.01$ and $* * * \mathrm{P}<.001$. 


\section{Supplementary Figures}

Supplementary Figure 1. Mean average dose for the targeted and non-targeted subvolumes the entire experimental groups for a) base, b) middle and c) apex irradiated mice.

Supplementary Figure 2. Representative treatment plans from Muriplan for each of the cradica subvolumes; a) base, b) middle and d) apex.

Supplementary Figure 3. Cardiac systolic functional changes measured as the ejection fraction EF at a) 40 weeks and b) 50 weeks post treatment. Data are presented as an average of 6 mice per treatment group \pm standard error of the mean. Significance values were classified as $* \mathrm{P}<.05, * * \mathrm{P}<.01$ and $* * * \mathrm{P}<.001$.

Supplementary Figure 4. LVPW thickness for all experimental arms at: a) baseline, b) 10 weeks, c) 20 weeks after treatment. Data are presented as an average of 6 mice per treatment group \pm standard error of the mean. Significance values were classified as $* \mathrm{P}<.05, * * \mathrm{P}<.01$ and $* * * \mathrm{P}<.001$

Supplementary Figure 5 Dose Volume Histograms (DVHs) for heart volume after radiation delivered to a) base, b) middle and c) apex regions of the heart. Corresponding DVH for the left lung after the radiation has been delivered to d) base, e) median and f) apex of the heart. 